* Doutor em Direito pela Fadisp. Professor e Coordenador do Curso de Direito do Centro Universitário de Anápolis - Unievangélica, campus Ceres. E-mail: valtecino@, gmail.com

\section{Teoria das Janelas Fechadas e Coculpabilidade: A Fábula de Esopo Na VIDA Real}

\author{
Theory of Closed Windows and Coculpability: The \\ FABLE OF AESOP IN REAL LifE
}

Valtecino Eufrásio Leal*

Como citar: LEAL, Valtecino Eufrásio. Teoria das janelas fechadas e coculpabilidade: a fábula de Esopo na vida real. Revista do Direito Público, Londrina, v. 15, n. 1, p. 46-60, abr. 2020. DOI: $10.5433 / 24157-108104-1.2020 v 15 n 1 p$. 46. ISSN: $1980-511 \mathrm{X}$

Resumo: O que se propõe com este ensaio é demonstrar que a sociedade de riscos em que vivemos, de ambientes favoráveis à cisão e à estratificação social, formata extremos sociais entre seres excluídos que enxergam outros usufruir de bens e riquezas conquistadas por meritocracia. A partir de uma releitura de uma fábula de Esopo, teoriza-se, acerca de uma das vertentes da onda de crimes que permeia pelo Brasil, decorrente da inércia daqueles homens de bem que, situados em melhores pontos de partida, omitem-se e deixam de formatar ações inclusivas em favor de seres fragilizados e vulnerabilizados pela incapacidade de disputar lugares de realização na corrida neocapitalista. Ao final, sugere-se um quadro de colidência entre objetivos e ações institucionais, onde a omissão da coletividade, soma-se à ineficácia estatal para outorgar e dar cumprimento e efetivação à plena cidadania.

Palavras-chaves: Crimes. Exclusão social. Justiça. Fábula. Janelas fechadas.

Abstract: The purpose of this essay is to demonstrate that the risk society in which we live, an environment favorable to division and social stratification, forms extreme social inequalities between those excluded from our capitalist society and those included without any social and economic disadvantages. From a re-reading of Aesop's fables, one theorizes about the origin of the wave of crimes that permeates Brazil today, which clearly result from the inertia of those men of good who, located in better starting positions, omit themselves in the creation of inclusive programs in favor of weakened and vulnerable individuals that are incapable of disputing equally in our society's neocapitalist race. In the end, we suggest a framework of institutional objectives and actions, because collective consciousness is important 
in increasing state efficiency as a means for granting the right to full citizenship.

Keywords: Crimes. Social exclusion. Justice. Fable. Windows closed. 


\section{INTRODUÇÃO}

Nas últimas décadas muito se tem discutido sobre rupturas na convivência pacífica entre os povos, protagonizadas em grande soma, pela má distribuição de rendas e bens, e, em menor parcela, pelo fato do alcance de conteúdos penais incriminadores, forjarem-se, em doses maiores, em desfavor de povos ou grupos sociais mais fragilizados. Nesse último caso, as crises de utopias e de tensões na eficácia das sanções penais e na necessidade de responsabilização de agentes criminosos, à luz de preceitos mínimos de justiça, intensificam a desconfiança nos efeitos sociológicos acarretados pela prisão. Em realidade, quem se acha nesse submundo, conforme se verá, além de sofrer efeitos psicológicos, inerentes à adoção de atitude infantil e regressiva, submete-se a um processo de desculturalização, por meio de qual perde os hábitos corriqueiros numa sociedade em geral.

Assim, a busca do fim punitivo encenador do medo que oresultado aflitivo tende a representar, somado à ilusão da ressocialização, contrasta com tendências teóricas como a coculpabilidade, as janelas quebradas e o funcionalismo sistêmico, em movimentos de investigações divergentes, mas que se entrecruzam em retrabalhos penais justificadores da procura por equalização e pacificação social. Esses lineamentos epistemológicos penais de inspiração recente, esforçam-se para explicar o risco da convivência social e parecem flertar com a missão de se pensar em mecanismos eficazes de contenção da criminalidade crescente a partir de um sistema que venha a harmonizar relações humanas conflituosas - por crises de desigualdades - e a tutela daqueles bens jurídico-penais essenciais, proclamados como inevitáveis para o viver em comunidade.

Deve-se ressalvar, numa lógica de coisas humanas injustas, que no Brasil, nesses últimos tempos, algumas poucas exceções dimensionadas em contornos persecutórios penais específicos, levaram a pressuposições indicativas de uma virada de rumos, a exemplo de algumas megaoperações avassaladoras no âmbito federal, a exemplo da sanguessuga e da lava jato, a primeira, deflagrada em maio de 2006 pela Polícia Federal para investigar a máfia das ambulâncias e materiais hospitalares e a segunda, deflagrada em março de 2014 e com seu pico de maior ebulição entre 2016 e 2017 , a fim de investigar um grande esquema de lavagem e desvio de dinheiro envolvendo a Petrobras, grandes empreiteiras e centenas de políticos .

Mas excluídas essas investigações quase cinematográficas, ninguém há de negar que em grande soma, os crimes e as punibilidades, em nações emergentes, por suas desigualdades quase permanentes, acometem em maior grau as pessoas pobres, os afrodescendentes e outros seres hipossuficientes. Estes humanos criminalizados, para o padrão ocidental, situados fora da curva em relação àquilo que se espera do homem mediano, figuram na condição de excluídos das conquistas políticas mais pujantes e tornam-se vítimas de garantias humanas corrompidas. Razões como essas, mundo afora, levaram e ainda estão a conduzir grandes massas de humanos sem voz, a lutar por algum tipo particular de justiça, ainda que esta resida na violação das legislações, em regra, estruturadas e elaboradas, por pensadores não incluídos no rol de homens atirados às sub- 
existências.

Esse contexto de recorrência de sortilégios em série, somado à desesperança e às amarras de um Estado sem pavimentação para a justiça prospectiva, restaurativa e distributiva, parece desincumbir empilhamentos humanos esquecidos em submundos, das análises e pensares éticos de laboratório e por alguma razão, alijados das liberdades civis, garantias políticas e dos direitos sociais prometidos pelo socialismo liberal, esses seres, sentem-se desimpedidos e em certa medida, compelidos, tanto para a afronta à vida alheia, como para a violação aos territórios federados, ou às terras particulares e ainda, marcham rumos às migrações e invasões, em busca de melhores expectativas no próprio país, ou em mobilidades do tudo ou nada, ao cruzarem fronteiras de nações mais avançadas economicamente. São os estranhos, que rondam as portas de seres domiciliados em pátrias ocidentais, migram de terras em conflitos e/ou crises e alguns deles, tendem a protagonizar condutas criminosas e a ecoar gritos de alerta para erros de justiça não admitidos, mas implícitos, situados em ações de individualistas neoliberais e seus mitos e teorias de autoproteção coletiva, ao longo dos séculos. Esse entremear de direitos, deveres e equívocos, deturpam as significações do acesso à justiça e provocam de modo indireto, atrocidades e prejuízos para boa parcela de humanos.

Neste ensaio, a problemática que se levanta sobre as janelas fechadas e uma fábula de Esopo, ocorre por meio de argumentações empíricas e da compilação de dados bibliográficos, a fim de convergir para questionamentos das tensões que o próprio Estado cria entre justiça social e igualdade formal e se procura, como hipótese de estudo, tatear por luzes em favor de incursões teóricas que despertem um repensar sobre nossas qualidades ou defeitos de lobos orientados pela simpatia fetichizada às desventuras das acumulações econômicas. As estratégias neocapitalistas, de algum modo, nos impedem de utilizar a racionalidade com o fim de encontrar consensos para as crises de indiferenças e desumanidades a que se subjugam homens e mulheres, encantoados pelas dificuldades e destituídos de perspectivas, que tendem a transformar-se em lobos da infração penal, ávidos por alguma chance de sobrevivência.

\section{A FÁBULA DE ESOPO NA VIDA REAL}

$\mathrm{Na}$ linha teórica objeto de defesa desta pesquisa, abre-se parênteses para mimetização de uma Fábula, com o propósito de subsunção da fantasia aos argumentos da realidade, a seguir desenvolvidos. Reinterpreta-se aqui de modo expansivo, um dos Contos de Esopo, traduzido por La Fontaine, La Cigale et la Fourmi, reescrito a partir da Fábula de Esopo, com a seguinte tradução livre $^{1}$ :

\footnotetext{
1 Texto original: La Cigale, ayant chanté Tout l'été, Se trouva fort dépourvue Quand la bise fut venue: Pas un seul petit morceau De mouche ou de vermisseau. Elle alla crier famine Chez la Fourmi sa voisine, La priant de lui prêter Quelque grain pour subsister Jusqu'à la saison nouvelle. "Je vous paierai, lui dit-elle, Avant l'Oût, foi d'animal, Intérêt et principal." La Fourmi n'est pas prêteuse: C'est là son moindre défaut. Que faisiez-vous au temps chaud? Dit-elle à cette emprunteuse. - Nuit et jour à tout venant Je chantais, ne vous déplaise. - Vous chantiez? j'en suis fort aise. Eh bien! dansez maintenant.
} 
A cigarra, tendo cantado durante todo o verão, quando o vento forte e as chuvas vieram do norte, sem condições de voar, bateu à porta da formiga e implorou que lhe emprestasse alguns grãos para sobreviver, durante a temporada de inverno e disse à formiga: - Eu vou te pagar, o principal e os juros. A formiga disse que não estava emprestando e indagou à cigarra: - O que você fazia durante o verão? Ela respondeu: - Noite e dia, todos se interessavam, então eu cantava para agradar. A formiga retrucou: - Ah, enquanto eu trabalhava, você cantava. Hoje estou muito confortável. Muito bem, então agora, dança! (LA FONTAINE, 2014, p. 2, tradução nossa).

Denota-se do conto em questão e da própria natureza, que as formigas foram concebidas como seres privilegiados e por isso, premiadas pelo senso de organização e pela força para o trabalho. Por meio de duras jornadas em algumas estações, elas acumularam alimentos para as estações chuvosas. Durante a longa estiagem, as cigarras, sem similar pré-condição para o senso de autodeterminação e luta, tiveram somente o dom de assoviar alegremente. Chegado o inverno, as primeiras, com aprovisionamento suficiente, fecharam suas portas para as últimas e reproduziram bom exemplo de conduta meritocrática.

Essa estória, conquanto simplista, não se apresenta tão destoante da história das relações humanas e nós, racionais, instigados pelas maldades silenciosas do capitalismo, reproduzimos a fábula na vida real. De fato, nas sociedades, o valor do mérito sobressai e homens e mulheres com melhores pontos de partida, conquistam bens e status ao longo da vida e passam a merecer um laissez-faire singularizado pelas disputas de mercado livre e pela realização da desejável estabilidade financeira. Quem age dessa forma, de alguma maneira, busca o bem-estar típico do liberalismo econômico. Em outras palavras, a partir da década de 70, as reflexões acadêmicas predominantes, passaram a acenar para um modelo de neoliberalismo, mas não houvera, ainda, o completo divórcio do individualismo. Piketty (2014, p. 114-115) relembra a natureza da riqueza no Século XIX e concentra-se nos romances de Balzac e Austen. Assevera que as terras e as dívidas públicas formatavam as rendas e as riquezas naquela época, mas dois Séculos depois, ainda vivemos as mesmas desigualdades e concentração de bens.

Nesse sentido, a seleção natural ou divina ora em destaque, muito raramente é avaliada academicamente e menos ainda chega a ser debatida em caráter de preocupação social e raros são os momentos de indagações para o fato de alguns, mais do que outros, receberem dádivas ao acaso ou por uma lei universal. Contudo, nítido transparece que essas prerrogativas relativamente superiores, favorecem alguns, sobremaneira, na corrida humana. Essas pessoas, as formigas, orientam suas vidas por escolhas razoáveis e dons de conquista e com seu poder de luta e trabalho, tornam-se etnocentristas e privilegiadas pela capacidade de organização, autonomia e autodeterminação.

Noutros recantos mais nefastos, localizam-se os seres destituídos de pontos de partida em níveis elevados e isso, os impedem de lançar-se aos ventos com a mesma intensidade ou com o ritmo contumaz das formigas e assim, por não nascerem com a aptidão para a evolução e sem o adequado grau de emancipação, ficam relegados aos subempregos, ao mercado informal ou ao desemprego, submersos nas expectativas lineares de que um dia, um milagre venha a acontecer, ou 
que apareça dos céus um Messias salvacionista. É de advertir-se que a denominação acima inerente ao ponto de partida é um conceito diferente da posição de igualdade original concebida por Rawls. Esse contratualista, em sua Teoria da justiça, compreende que um acordo ou consenso hipotético pode ser imaginado numa posição original de equidade. Para ele, pessoas racionais podem fixar uma contratação social, desvestindo-se de valores ou experiências mentais anteriores de quais já são possuidoras e assim, poderia prevalecer a ideia do justo e do bom, num quadro de justiça com equidade (RAWLS, 2000, p. 499-500), mas nisso há uma diferença do imperativo categórico de Kant, pois na teoria de justiça, a prática de um bem não é um dever ou algo obrigatório ${ }^{2}$. $\mathrm{Na}$ definição Rawlsiana, os princípios de justiça seriam escolhidos sob um véu da ignorância, em qual ninguém conheceria sua posição inicial na sociedade, incluindo-se sua classe, seus atributos, seus talentos, sua força e outras qualidades e por isso, no início, todos estariam em situação de equivalência. Entretanto, neste ensaio, ao se utilizar da expressão ponto de partida, menciona-se acerca das qualidades originais de alguém, como intelecção, força física, autodeterminação, boa gestão e outras, para alcançar posições meritocráticas na sociedade.

Acentuam Zaffaroni e Pierangeli (2015, p. 610) que a sociedade não tem como brindar todos com as mesmas oportunidades e desse meio, em grande parte, nascem os inconformados e aqueles que decidem, enquanto "cigarras" excluídas, a violar o sistema ou a atacar, como última ratio, as formigas dominantes, o que em tempos passados foi motivo de inquietação por Rousseau (2003, p. 31), defensor da ideia de que “[...] os homens não podem criar novas forças, mas só unir e dirigir as que já existem, o meio que têm para se conservar é formar por agregação uma soma de forças que vença a resistência, com um só móvel pô-las em ação e fazê-las obrar em harmonia.” Para Hobbes (2015, p. 136) “a causa final, fim ou desígnio dos homens (que apreciam, naturalmente, a liberdade e o domínio sobre os outros), ao introduzir a restrição a si mesmos que os leva a viver em Estados, é a preocupação com sua própria conservação e a garantia de uma vida mais feliz". Ao teor dessas arguições, percebe-se que o objetivo da vida em comunidade, é a busca da autopreservação e da vida feliz. Entretanto, com o recrudescimento das violações penais impeditivas do viver harmonioso e a ineficácia estatal para soluções adequadas, nasceram preocupações em acadêmicos como Roxin (2009) e Jákobs (2007), mediante pensares à volta de um direito funcional e protetivo do sistema, que serão objeto de estudo noutra pesquisa, brevemente.

Assim, conviver coletivamente é a ordem, mas os riscos nos conduzem a uma sociedade do medo e, invés de nos solidarizarmos com a carência, nos unimos pelo sentimento do medo (BECK, 2010, p. 60). Portanto, a emergência do medo, faz fluir nossos comportamentos para intersecções consentâneas com as ações praticadas por agentes estatais e com condutas criminosas de significados e ressignificados sociopolíticos. A repercussão estigmatizadora nesse estado de precarização na garantia das liberdades civis, é a de uma nação que grassa pelo salve-se quem puder, em culpa de menor grau atribuível ao Estado - que não pode e nem deve intrometer-se na vida das pessoas com um direito penal máximo - e responsabilidade de maior grau, nos termos

2 “'...] existe a interessante classe dos atos supererrogatórios. São atos de benevolência e misericórdia, de heroísmo e auto-sacrifício. Praticá-los é um bem, mas não constitui obrigação ou dever para ninguém” (RAWLS, 2000, p. 125). 
aqui defendidos, imputável à sociedade - que deveria experimentar algum tipo de sanção - cujos membros comportam-se pelo livre mercado, ainda ao estilo do utilitarismo benthaniano e pouco importam se no degrau debaixo, há homens, mulheres e crianças, mergulhados em submundos. Afinal, em contextos identitários de sinergias europeístas e/ou norte-americanistas, para as leis capitalistas funcionarem bem, é preciso que exista, de fato, dois eixos opostos, um, dos dominadores/ usufruidores das riquezas e outro, dos seres dominados, que levam a vida, em dificuldades, para sustentar as engrenagens do sistema.

Não há explicação única para esses fatores que imbricam em percepções sociológicas, filosóficas, políticas e jurídicas. Todavia, sinaliza-se para uma resposta, em razão de, no Brasil, em diversas localidades - não só em grandes centros - as formigas se encastelarem em lugares aparentemente seguros, com muros altos, câmeras de segurança, cercas elétricas, sistemas de alarme e assimilam alguma sensação de proteção do mundo externo. São vidas simbolizadas pela rotina de evasão das cigarras, algumas destas últimas, revoltadas e armadas para embates. Decididamente, as primeiras tendem a confiar e a esperar pelo garantismo e pela segurança prometida utopicamente pelo estado democrático e sequer entreabrem suas portas e janelas para um mundo de justiça distributiva ou para diálogos que possam auxiliar as excluídas em seus dias perenes de tempestades e cataclismos.

Enquanto as janelas se fecham, em nichos específicos como presídios, algumas favelas dominadas por associações criminosas e em lugares de pouca presença ostensiva das polícias, o movimento de irresignação de boa parcela das cigarras progride de modo assintomático, quase numa operação silenciosa de recrutamento de pseudos inimigos. Mas a rotina social da maior parte, ainda segue contida por algum senso ético, em consensos dialógicos, sujeitando-se a atribuir culpa à corrupção, às formigas gestoras, aos políticos e às classes médias e altas, fator este com aptidão para manter um precário controle na segurança comunitária. Como não existem certezas matemáticas nessas relações humanas vulnerabilizadas, aqui ou acolá, evoluem os inconformismos e alguns avançam para os ataques diretos, potencializando-se as ondas avassaladoras de roubos, assassinatos e tantas outras condutas criminosas que atemorizam até mesmo aqueles observadores menos incautos e habituados aos tempos de cólera.

Em contextos humanos como esses, advertem Zaffaroni e Pierangeli (2015, p. 547):

[...] se a sociedade outorga, ou permite a alguns, gozar de espaços sociais dos quais outros não dispõem ou são a estes negados, a reprovação de culpabilidade que se faz à pessoa quem se tem negado as possibilidades outorgadas a outras, deve ser em parte compensada, isto é, a sociedade deve arcar com uma parte da reprovação.

Nessa corresponsabilização, a sociedade inerte, deve arcar com sua parcela de reprovação, pelas condutas infracionais das cigarras. Contudo, nesse artigo científico, se deseja contextualizar outra vertente, embora próxima do pensar funcionalista de Roxin e das reflexões acima de Zaffaroni e Pierangeli. As bases do funcionalismo teleológico de Roxin (2002, p. 205) tem correlação direta 
com os fins da pena e com valores político-criminais e algo de suas inspirações pode ser apreendido na seguinte passagem:

Os adeptos desta concepção [funcionalismo] estão de acordo - apesar de várias divergências quanto ao resto - na recusa às premissas sistemáticas do finalismo e em partir da ideia de que a construção sistemática jurídico-penal não deve orientar-se segundo dados prévios ontológicos (ação, causalidade, estruturas lógico-reais, etc.), mas ser exclusivamente guiada por finalidades jurídico-penais.

Quanto aos substratos do crime, Roxin (2009, p. 41) aduziu que somente a criação de riscos não permitidos devem proporcionar a imputação objetiva e assim defendia: “O legislador só deve proteger bens jurídicos e, em consequência, deixar intacta a liberdade de atuação do cidadão. Por sua parte, o aplicador do Direito tampouco deve proteger os bens jurídicos de uma maneira absoluta, senão unicamente frente às lesões produzidas mediante riscos não permitidos".

Nessa perspectiva, se a fração de seres sociais com melhores pontos de partida, na medida da justa necessidade de convivência social, deve merecer responsabilização, pela exclusão da outra parte menos favorecida, também deve sopesar-se, como segunda fonte de responsabilização, a inércia ou ausência de ações ou lutas civis organizadas que possam aquebrantar as perversidades que o capitalismo incute nos seres humanos. Essa segunda fonte, consistente na omissão das formigas, aqui delineada, por fechamento de suas janelas, figura como modalidade de "criação de um risco" indutor de revoltas e infrações penais.

Não é o objetivo deste breve ensaio, delimitar acenos em favor da justiça distributiva aristotélica ou ao modelo teórico defendido por Franco Montoro. Em Aristóteles (2009, p. 108), nota-se que uma das espécies de justiça particular "[...] é a que se manifesta nas distribuições de magistraturas, de dinheiro ou das outras coisas que são divididas entre aqueles que têm parte na constituição (pois em tais coisas alguém pode receber um quinhão igual ou desigual ao de outra pessoa) [...]." Em sentido divergente, Montoro (2011, p. 220-221) aponta que a justiça distributiva é “[...] a virtude pela qual a comunidade dá a cada um de seus membros uma participação no bem comum, observada uma igualdade proporcional ou relativa." Por essa premissa, pelo simples fato de integrar uma coletividade, a pessoa faz jus aos bens comuns. Além disso, a igualdade deveria parametrizar-se pela capacidade do indivíduo socialmente. Seja qual for o conteúdo do direito, quem tem mais ou pode mais, deve compreender que as reservas planeta pertencem a todos.

O propósito desta pesquisa é reafirmar que no Brasil, há polarizações e as formigas sectaristas, literalmente lavam as mãos ante grupamentos de excluídos e alguns destes últimos enxergam, frise-se, como única alternativa o ataque ou as condutas criminosas, por não se contentarem em apenas assistir ao banqueteamento dos seres com maior privilégio, o que, do ponto de vista humanitário, viola qualquer preceito de justiça. Fenômenos como esses, se aceitos socialmente, alerta Costa (2008, p. 107), tendem a “[...] atestar que aqueles que vivem na miséria sofrem desproporcionalmente uma série de violações de direitos humanos” e nessa linha, o 
movimento desses direitos "[...] corre o risco de perder a sua credibilidade e seu apelo moral, se não for capaz de levar em consideração o sofrimento de milhões de pessoas [...]” (COSTA, 2008, p. 108).

Por esses motivos, as investigações por teorias ideais de responsabilização penal direcionada aos grupos sociais dominantes ou com melhores pontos de partida, são de alta relevância, em Estados democráticos de modernidade tardia e sem inspirações para ativismos sociais concretos, superadores da mera atividade pensante (MARX, 1999). A teoria ou o pensamento humano, para nada serve, senão transformado para a praxis, consistente em ações concretas socialmente, reveladoras da produção e do trabalho. Para Marx (1999, p. 5), “[...] É na prática que o homem tem que demonstrar a verdade, isto é, a realidade, e a força, o caráter terreno de seu pensamento. $\mathrm{O}$ debate sobre a realidade ou a irrealidade de um pensamento isolado da prática é um problema puramente escolástico". Mais adiante, Marx (1999,p. 6) continua: “A coincidência da modificação das circunstâncias e da atividade humana só pode ser apreendida e racionalmente compreendida como prática transformadora".

Não se olvida que determinados valores devem permear o viver em sociedade e nessa modalidade de estrutura básica em que certos princípios são obedecidos (RAWLS, 2000), não se deve incitar somente os comportamentos de disputas meritocráticas, sem que isso reverta em favor de todos. Uma nação que se intitula solidária e justa, deve envolver seu povo, os entes federados e as autoridades investidas nos poderes da República, numa coalização global para respostas e políticas públicas em favor de seres e grupos em exclusão.

\section{TEORIA DAS JANELAS FECHADAS VERSUS COCULPABILIDADE}

Pelo plano teórico até aqui esboçado, as janelas fechadas tendem a maximizar conflitos sociais. Por esse prisma, o estado de natureza hobbesiano pode explicar alguns dos pontos de argumentação e questionamentos e quanto a isso, ninguém discute que a sociedade brasileira, a partir da cisão de castas e dos status financeiros de algumas estratificações sociais, confere a algumas pessoas, condições de vedar suas janelas, numa antecipação aos perigos dos ataques de autoria daqueles seres hipossuficientes que ali poderiam lançar suas iras, em busca da obtenção de algum ajuste distributivo. Todavia, quanto mais as janelas se fecham e as formigas buscam proteção, proporcionalmente, o estado de natureza tende a aflorar-se nas cigarras ou em algumas delas, que de certa maneira, eclodem ou tendem a eclodir, em seus inconformismos, para, em algum momento inesperado, reorganizar ou reinventar investidas infracionais.

Portanto, não se ignora a relevância das reflexões de teorias como as janelas quebradas e que a desordem é indutiva de desordem. Mas também é preciso reconhecer que em nações emergentes e com alta quantidade de integrantes dos poderes da República envolvidos em escândalos de corrupção, diferentemente de lugares desenvolvidos economicamente, comportamentos infracionais tornamse banalizados, num reproduzir do comportamento encenado pelos ocupantes de cargos políticos. Mas em linha diametralmente oposta, o cerrar de portas e janelas para seres em desigualdade, 
retroalimenta iras adormecidas e se não houver correções de rumos, com o plagiar de condutas, o caos pode generalizar-se nas comunidades, em velocidade e tempo não mais controlável pelos poderes dirigentes, combalidos e incumbidos da repressão penal institucionalizada e da outorga de segurança pública.

Por essa teoria das janelas fechadas que flerta de alguma maneira com a coculpabilidade penal e tem como mote um despertar para os perigos da quebra do contrato social e do controle, mensura-se, empiricamente, a inércia dos poderes e dos homens de bem, que, apesar de presenteados por dádivas divinas ou naturais, passam pelo mundo com o olhar voltado para seus muros, num ignorar perigoso do outro. Enquanto isso, os bens finitos do planeta, que deveriam se prestar para um construir de pontes e inclusão, ficam reservados a alguns castelos que abrigam agentes do pacto social, injustos.

Nas ciências sociais, como afirmou Bauman (2016, p. 36-37), num de seus derradeiros estudos, é concebível que o medo visível e tangível de adversários específicos "[...] é um pouco mais suportável do que os temores dispersos, difusos e flutuantes, de origem desconhecida". No Direito Penal isso também é inteiramente aplicável. Há número considerável de pessoas que sujeitam-se aos locais de janelas quebradas, cônscias de que o Estado, a realidade socioeconômica e a sociedade civil nada oferece a elas, a não ser um primado normativista de odiosa e mera aplicação da lei. Esses e outros milhões de homens e mulheres, no Brasil, subservientes dos algozes da jornada dos mercados, de algum modo, tendem a se rebelar e a tornar-se inimigos incertos e difusos, nos momentos em quais as crises existenciais se acirram.

A denominação sociedade civil que adota-se neste estudo, aproxima-se da concepção de Oliveira e Haddad (2001, p. 62), no sentido de que a significação faz contraponto com o Estado e "[...] corresponde à população de cidadãos, ou esfera privada, e abrange suas variadas formas de organização e expressão - com ou sem fins lucrativos, podendo ser legalmente constituídas ou espontâneas e informais".

Algumas indagações simétricas podem surgir a essa altura: como explicar, corresponsabilizar e quotizar deveres para grupos ou pessoas que estejam em posição social de conforto econômico-financeiro, pelas práticas criminosas cometidas por pessoas pertencentes a grupamentos de excluídos sociais? Como fazê-las de fato, abrir suas janelas para visualizar o que acontece no mundo exterior? Qual o melhor escrutínio humanista para fazê-las entender que se o crime está disseminado na sociedade por razões de pobreza endêmica e por desigualdades recorrentes, não mais é possível exigir ou esperar que apenas o Estado possa resolver a emergência dessas ameaças?

Não são esses questionamentos de respostas prontas, mas a se construir. Todavia, é plenamente inexorável que arranjos de justiça sejam investigados. Num primeiro argumento, perceba-se que a República Federativa do Brasil possui sistemas impactantes de arrecadação financeira que a ela outorga o direito de se associar e apropriar-se de boa parte das economias e ganhos dos brasileiros. Apesar das metáforas de ajuda estatal a pessoas hipossuficientes, também é evidente que o sustentáculo dessas arrecadações são justamente os trabalhadores e suas rendas. 
Ao mesmo tempo, pesquisas científicas estão a confirmar que, embora esse furor arrecadatório, há frustrações de gestão em muitas frentes ${ }^{3}$, que impactam e refletem-se nos amontoados de pessoas aprisionadas em estabelecimentos penais, na oferta precarizada de educação básica a crianças e adolescentes, no caos de oferta da saúde pública, nas corrupções em série, na inoperância do Estado prestacional, dentre outras. Em suas pesquisas, Salvador (2012) demonstra que os trabalhadores pagam a conta do custo Brasil. Exemplificam que no ano de 2009, foram eles, os responsáveis por 65,58\% das receitas arrecadadas pela União, Estados, Distrito Federal e Municípios e chegaram a pagar, R\$110,86 bilhões de tributos diretos, ou seja, cinco vezes mais do que os bancos. Conclui que nosso sistema tributário privilegia a acumulação capitalista e onera os mais pobres e assalariados, que pagam a conta. Esse montante arrecadado deveria reverter em favor dos próprios grupos de trabalhadores, mas o que se vê é a injusta distribuição de rendas.

Como segundo argumento, é de se ponderar que muitos empreendimentos sociais privados têm alcançado regular sucesso no livre mercado, alguns, com empréstimos vultosos junto ao Banco Nacional de Desenvolvimento Social, o que apenas confirma que as arrecadações e os tributos revertem em favor de empresários e possuidores de rendas. Nesse contexto, não se pode prescindir de se delinear nesta pesquisa, um inicial esforço hermenêutico para se refletir sobre alguma tábua de salvação garantista, na crença de que na sociedade civil pode situar-se a esperança da maior colaboração e solução, se suas estruturas organizadas assumirem o enfrentamento e seus membros deixarem de, apenas, fechar suas janelas. É inevitável, nesse pensar expansionista, a encampação dos riscos presentes, com o propósito de atenuar o hiperdimensionamento dos perigos futuros. A partir desses argumentos, várias são as hipóteses e escolhas pluralistas e algumas sugestões passam a ser formatadas, nesses termos:

a) é indispensável, pensar numa reforma legislativa ou normativa sistêmica, a fim de se atribuir a todos os integrantes das comunidades, o dever expresso (e não somente uma faculdade) de assumir responsabilidades. Por esse enfoque, o tecido social não pode apenas assistir e clamar por providências. É dever de todos adotar mecanismos de fiscalização obrigatória, quiçá por comissões civis, no âmbito da educação, dos presídios, do executivo, do judiciário, do legislativo e das finanças públicas. Também deveriam existir, atuações ou manejos via abaixo-assinados diretos ou outra forma de deliberação célere, como um plebiscito eletrônico, notadamente se existem mecanismos disponíveis nesse mundo da informação tecnológica. Isso deslegitimaria o legislativo e outros poderes para a avocação de plebiscitos ou referendos físicos (convenhamos, ineficazes, para não dizer inúteis, numa nação em que grande parte dos homens públicos que se proclamam defensores das conquistas do constitucionalismo social, estão sob investigações diuturnas e a eles, ironicamente, caberia, por exemplo, a iniciativa de deflagrar consultas como essas). Esses instrumentos, da forma como concebidos, mostram-se totalmente acéfalos e no modelo previsto, tendem a emancipar o parâmetro de desilusão moral desses tempos sombrios. Um bom começo seria repensar o modo de se instrumentalizá-los e readaptá-los a esses tempos de informações ultravelozes;

3 Veja-se nesse sentido, os artigos de Bittar (2010), Costa (2008) e Arruda, Bertolini e Cunha (2016). 
b) é urgente deliberar também sobre o meio mais adequado de se integrar as comunidades, numa convergência de olhares para as desigualdades e distorções sociais e advertir sobre a superação de comportamentos cada vez mais utilitaristas e separatistas. Se os fenômenos da violência se disseminaram e o Estado não mais consegue outorgar um enfrentamento eficaz, é inquestionável a inutilidade de discursos sociopolíticos de combate e punibilidade aos membros mais refratários das comunidades e noutro viés, é preferível dar à nova morfologia social, a oportunidade, senão o dever, de envolver-se numa rede célere de informações, orientada pela autodefesa (alguns comportamentos podem ser divulgados reiteradamente pela mídia), pela não violência, pelo diálogo de solução pacífica dos conflitos sociais e o mais importante, pela inclusão e auxílio direto de grupos em situação de precarização. Parte dessas sugestões são inerentes a um significado civilizatório das lutas sociais contra a violência, apontado como ideal por Lima, Ratton e Azevedo (2014) e pode atenuar exclusões e estratificações de classes, além de ofertar aos integrantes das comunidades, a chance de visualizar o que acontece além das janelas fechadas - quem se isola em seus muros, corre o risco de estar sozinho, quando seu espaço for violado;

c) há propagação e publicização intensa de que para o crime, o funcionalismo sistêmico seria a melhor saída; a prisão seria a solução; os efetivos das polícias deveriam ser aumentados; o Estado, em seu papel de guardião das garantias fundamentais, seria obrigado a conferir a eficaz segurança pública; e que as penas deveriam merecer exasperação. Isso tudo, porém, são utopias e as escolas, a mídia, os ambientes acadêmicos, enfim a sociedade, podem agir proativamente e em caráter de colaboração recíproca, para encampar e adotar fundamentos de ensinagem, boas práticas éticas e solidariedade, por meio de diálogos de aproximação entre os povos; visitação curricular organizada de estudantes em favelas e comunidades carentes; palestras educativas em comunidades e escolas fragilizadas; reorganização no âmbito das prefeituras para atendimento prioritário no interior das comunidades carentes; e integração de instituições socializadoras diversas como grupos familiares, empresas, entidades religiosas, agremiações esportivas e a imprensa, na missão de auxiliar, orientar e oportunizar alternativas a grupos hostilizados, fatores esses essenciais para a superação conjunta das crises sociais;

d) nessas lutas de reaproximação, as mídias sociais, como whatssaap, facebook e outras, podem e devem ser utilizadas, mais intensamente, de modo organizado, com vista a fomentar mudanças e para apresentar/divulgar resultados decorrentes da integração e também para a quebra de paradigmas de exclusão recorrente.

As sugestões e acepções críticas que ora se preconizam, comportam olhares para rupturas latentes, nos sistemas políticos e na justiça penal (polícias, academias de polícias, judiciário, presídios, manicômios e instituições da justiça penal) ${ }^{4}$ e para o curso quase irrefreável das crises de convivência. Se esses dilemas pluralizam-se, não há mais tempo para longas reflexões políticas ou de laboratórios e ademais, resulta em romantismo pueril crer somente em soluções estatais. No âmbito penal, o país viaja acelerado rumo a um abismo e hoje, mais do que outrora, abre-se momento para algum tipo de repactuação na sociedade civil e nos poderes da república brasileira,

4 Nesse sentido, ver Bauman (2016) e Lima, Ratton e Azevedo (2014). 
para se conferir ao povo, mais representatividade para mediações e retomadas de percursos democráticos legítimos. O poder e o dever de atuação direta é do povo em várias frentes e no tecido social devem ser rearticulados esses movimentos de retomada. O puro sistema de substituição democrática de vontades coletivas vigente e a crença no Estado como o dirigente das vidas em comunidade, fracassou e ao longo das décadas, mostrou-se inapropriado e sobremodo fragilizado pelo alto índice de corrupção e de criminalidade que sitia as pessoas em dois extremos, um inerente à ausência de rumos de quem está em busca dias melhores e outro, simbolizado pela inércia dos dias de realizações dos humanos que já chegaram, mas não podem ser plenamente vividos.

\section{CONCLUSÃO}

Nessa era da informação, em que nossas vidas sujeitam-se à interferência direta e ao dirigismo estatal, em criações e recriações de controles de mercado e de participação direta dos entes federativos em nossos ganhos, e ainda, mediante a facilidade de comunicação e publicidade proporcionada pelas redes sociais, o Estado, que a todos conhece, ciente de quem e quantos são os homens e mulheres com melhores rendas e com privilégio de autonomia e autodeterminação, tem a missão de virar o leme para a mudança de mentalidade ou de valores, mas mostra-se ineficaz. Além do mais, em contornos constitucionais ${ }^{5}$, constituem objetivos fundamentais do Brasil construir uma sociedade livre, justa, solidária, além de erradicar a pobreza, a marginalização e redução das desigualdades sociais. Também é sua função fomentar, estruturar e publicizar ações e coalizões em favor de comportamentos de solidariedade e de responsabilidade por parte de grupos dominantes, muito além das posturas que se têm visto em vários momentos institucionais e políticos, favoráveis à tutela da filosofia neoliberal e das políticas expansionistas de cunho capitalista.

Nesse quadro de colidência entre objetivos e ações institucionais, não mais se pode negar que existe ineficácia estatal para outorgar cumprimento à efetivação da plena cidadania. Some-se a isso a destituição de valores cada vez mais pujante e o descomprometimento da maioria dos brasileiros situados em melhores pontos de partida, com a realização do próximo, isso muito em conta do individualismo motivado pelos ideais neoliberais. As informações analógicas de ontem foram superadas pela multiplicidade de dados desse mundo hiperglobalizado, o que facilita o papel do Estado de controlador das vidas cada vez mais digitais que vivemos, mas isso não significou ampliações ou melhoras na outorga de direitos e por esse contexto permeiam as abordagens críticas presentes, acerca da incapacidade estatal de manejar estruturas favoráveis à inclusão social e à justiça distributiva e no seu papel de interferir em publicidades e no eixo do poderio financeiro ainda que a livre iniciativa e a propriedade sejam tuteladas - seja a título de fazer chegar aos homens e mulheres bem situados economicamente, a realidade de um problema não solucionável pela mão governamental e que está a potencializar crises de convivência, ou para advertir que as janelas fechadas semantizam um prognóstico de repulsa em classes sociais mais pobres e favorecem o

5 Os objetivos fundamentais da nação brasileira estão previstos no artigo $3^{\circ}$ da Constituição Federal da República do Brasil, de 1988. 
nascedouro de novos conflitos insuscetíveis de quebrar status sociais, mas propensos ao aumento da insegurança e da injustiça social.

Desse modo, o Estado por si só, mostra-se incapaz de dar cumprimento ao constitucionalismo social e não mais se pode esperar que todas as soluções para as crises na sociedade, sejam solucionadas por essa forma de dirigismo. Diante disso, uma solução seria abrir nossas portas e janelas para o que acontece no mundo à nossa volta. Também é preciso agrupar forças, movimentos sociais, mobilidades, integração de empreendimentos empresariais, a mídia, instituições educacionais, religiosas, governamentais, não governamentais e muitas outras, para de fato e não somente nas teorias acadêmicas, se outorgar contribuições desejáveis para um mundo mais justo e solidário.

Ao fecharmos nossas janelas; ao deixarmos de praticar atos de benevolência e misericórdia, que não obstante, constitui-se como um bem e não como obrigação ou dever; e ignorarmos que além dos muros, há exclusões, desigualdades e gente sem voz, cobrimos nossas faces de um véu de maldade que nos impede de procurar/encontrar diálogos e meios para uma solução mitigadora desse status de luta diária pela sobrevivência, na dinâmica da vida ofertada por sociedades neocapitalistas. Notoriamente, repita-se, se alguns são dotados de dádivas que lhes conferem atributos físicos e psíquicos para melhor compreensão das leis que regem os mercados econômicos e a ciranda humana que facilitam escolhas e resultados, porém deixam de agir enquanto há ocasião, faz-se urgente a procura por estratégias ou diálogos, da parte desses Golias senhores dos melhores lugares sociais, sob pena de, em algum momento futuro, enfrentarem os Davis representados por amontoados humanos presos em grilhões prestes a estourar.

\section{REFERÊNCIAS}

ARISTÓTELES. Ética a Nicômaco. São Paulo: Artmed Editora, 2009.

ARRUDA, Geraldo Clésio Maia; BERTOLINI, Adriana Rossas; CUNHA, Jânio Pereira.

Desconstruindo a ineficácia dos direitos sociais: por uma reconstrução dos direitos sociais democrática, participativa e transnacional. Revista Brasileira de Políticas, Brasília, v. 6, n. 1, p. 271-292, 2016.

BAUMAN, Zygmunt. Estranhos à nossa porta. Rio de Janeiro: Zahar, 2016.

BECK, Ulrich. Sociedade de risco: rumo a uma outra modernidade. São Paulo: Editora 34, 2010.

BITTAR, Eduardo Carlos Bianca. Crise econômica e crise do Direito: a ineficácia dos direitos humanos e o modelo de desenvolvimento. Revista da Faculdade de Direito, São Paulo, v. 105, p. 495-508, jan./dez. 2010.

COSTA, Fernanda Doz. Pobreza e direitos humanos: da mera retórica às obrigações jurídicas: um estudo crítico sobre diferentes modelos conceituais. Revista Internacional de Direitos Humanos, São Paulo, v. 5. n. 9, dez. 2008. 
HOBBES, Thomas. Leviatã ou matéria, forma e poder de um Estado eclesiástico e civil. 2. ed. São Paulo: Martin Claret, 2015.

JÁKOBS, Günther; MELIÁ, Manuel Cancio. Direito penal do inimigo. 2. ed. Porto Alegre: Livraria do Advogado, 2007.

LA FONTAINE, Jean. La cigale et la fourmi. [S. l.]: In Libro Veritas, 2014. Disponível em: http://www.inlibroveritas.net/oeuvres/63/la-cigale-et-la-fourmi. Acesso em: 16 abr. 2017.

LIMA, Renato Sérgio de; RATTON, José Luiz; AZEVEDO, Rodrigo Ghiringhelli de (org.). Crime, polícia e justiça no Brasil. São Paulo: Contexto, 2014.

MARX, Karl. Teses sobre Feuerbach. [S. l.]: RocketEdition, 1999. Disponível em: http://www. ebooksbrasil.org/adobeebook/feuerbach.pdf. Acesso em: 26 abr. 2017.

MONTORO, André Franco. Introdução à ciência do direito. São Paulo: Editora Revista dos Tribunais, 2011.

OLIVEIRA, Anna Cynthia; HADDAD, Sérgio. As organizações da sociedade civil e as ONG's de educação. Cadernos de Pesquisa, São Paulo, n. 112, p. 61-83, mar. 2001. Disponível em: http://www.scielo.br/pdf/cp/n112/16101.pdf. Acesso em: 28 abr. 2017.

PIKETTY, Thomas. O capital no século XXI. Rio de Janeiro: Intrínseca, 2014.

RAWLS, John. Uma teoria da justiça. São Paulo: Martins Fontes, 2000.

ROUSSEAU, Jean-Jacques. Do contrato social. São Paulo: Martin Claret, 2003.

ROXIN, Claus. A proteção de bens jurídicos como função do direito penal. Porto Alegre:

Livraria do Advogado, 2009.

ROXIN, Claus. Funcionalismo e imputação objetiva no direito penal. Rio de Janeiro:

Renovar, 2002.

SALVADOR, Evilásio. Fundo Público e o financiamento das políticas sociais no Brasil. Serviço Social em Revista, Londrina, v. 14, n. 2, p. 4-22, jan./jun. 2012. Disponível em: http://www.uel. br/revistas/uel/index.php/ssrevista/article/view/12263/11632. Acesso em: 28 abr. 2017.

ZAFFARONI, Eugenio Raúl; PIERANGELI, José Henrique. Manual de direito penal brasileiro: parte geral. 11. ed. São Paulo: Revista dos Tribunais, 2015.

Como citar: LEAL, Valtecino Eufrásio. Teoria das janelas fechadas e coculpabilidade: a fábula de Esopo na vida real. Revista do Direito Público, Londrina, v. 15, n. 1, p. 46-60, abr. 2020. DOI: $10.5433 / 24157-108104-1.2020 v 15 n 1 p .46$. ISSN: 1980-511X

Recebido em: 05/03/2018

Aprovado em: 17/02/2020 